\title{
Jurnal Manajemen Bisnis
}

Program Pascasarjana Universitas Muhammadiyah Tangerang

ISSN: 2302-3449 I e-ISSN: 2580-9490

Vol. 8I No. 2, hal 98-104

\section{PENGARUH KOMPENSASI DAN KEPUASAN KERJA DENGAN KOMITMEN DOSEN DI UNIVERSITAS MUHAMMADIYAH CIREBON}

\author{
Ali Jufri \\ Universitas Muhammadiyah Cirebon \\ ali.jufri@umc.ac.id
}

Keyword
Keywords : Compensation,
Job Satisfaction and Lecturer
Commitment.

Commitment.
Abstract

This study aims to describe and interpret the effect of compensation and job satisfaction on commitment of lecturers at Muhammadiyah University of Cirebon. This research was conducted using a survey method. As the population is merely 257 employees which is more 100 (one hundred) people, the research was a sample study. In addition, the object of this study is 51 (fifty one) employees. There are three conclusions that can be taken: (1) There is a significant and positive influence between compensation to lecturer commitment. The significance of the effect of compensation on lecturer commitment can be seen from the result of the test which the t count is 8,377> 1,677 then $\mathrm{Ho}$ is rejected and $\mathrm{Ha}$ is accepted. The determination index is adjusted by 58,9\% and the remaining $41,1 \%$ is influenced by other unexamined factors. (2) There is a significant and positive influence between job satisfaction and lecturer commitment. The significance of the effect of job satisfaction on lecturer commitment is evidenced by the $t$ test which is calculated at 6.884> 1.677 so Ho is rejected and $\mathrm{Ha}$ is accepted. The determination index is adjusted by $49.2 \%$ while the remaining $51.8 \%$ is influenced by other unexamined factors. (3) There is a significant and positive effect between compensation and job satisfaction on lecturer commitment. This can be proven by the F test which is the calculated $F$ value of 47,624>3,18 and the determination index value adjusted $66.5 \% 33.5 \%$ is influenced by other unexamined factors.

C2019 JMB, All right reserved

\section{PENDAHULUAN}

\section{Latar Belakang Masalah}

Lembaga atau Institusi merupakan suatu organisasi yang memiliki visi dan misi dalam mencapai tujuan. Aktivitas yang terjadi dalam suatu Lembaga atau institusi biasanya selalu ditujukan untuk mencapai visi dan misi lembaga tersebut. Oleh karena itu, lembaga harus mengelola sumber daya yang dimilikinya, yaitu physical resource dan human resource melalui manajemen yang efektif dan efisien.

Dalam menghadapi kondisi 
perekonomian yang bergejolak dan disertai dengan meningkatnya persaingan yang sempurna, maka sangat diperlukan suatu performance pegawai yang prima dalam meningkatkan produktivitas kerja. Sehingga menghasilkan kemajuan bagi Lembaga atau institusi. Untuk mencapai performance pegawai, maka lembaga harus mampu memberikan kepuasan kerja tersendiri bagi pegawai melalui sistem dan kebijakan pemberian kompensasi. Sehingga akan terbentuk sinergi yang baik antara kompensasi dan peningkatan performance pegawai dalam pencapaian tujuan lembaga.

Banyak praktisi dan pakar manajemen hampir memiliki prespektif yang sama bahwa prestasi kerja dan produktivitas kerja pegawai akan meningkat bila kebijakan dan sistem kompensasi lembaga atau institusi dirancang sesuai dengan standar kesejahteraan hidup, sehingga merangsang pegawai untuk bekerja lebih keras dan berpartisipasi lebih tinggi guna memperoleh kepuasan kerja tersendiri bagi pegawai yang bersangkutan.

Selain penting bagi individu, kompensasi juga penting bagi organisasi karena mencerminkan upaya organisasi untuk mempertahankan sumber daya manusianya (Handoko, 2006). Gibson et.al (2000) mengemukakan sistem kompensasi yang efektif akan mempengaruhi perilaku individu, seperti keluar masuk, absensi, prestasi dan komitmen.

Komitmen merupakan suatu kondisi dimana anggota organisasi memberikan kemampuan dan kesetiannya pada organisasi dalam mencapai tujuannya sebagai imbalan atas kepuasan yang diperolehnya (Hodge dan Antoni, 1991). Griffin dan Ebert dalam Wardani (2006) mengemukakan bahwa Pegawai yang puas lebih berkomitmen dan setia karena secara psikis mereka merasa lebih diperhatikan oleh lembaga.

Pegawai yang berkomitmen tinggi sangat dibutuhkan oleh organisasi untuk mencapai tujuan yang telah ditetapkan, sehingga perlu diupayakan membina dan meningkatkan komitmen pegawai terhadap organisasi melalui kompensasi yang memuaskan. Jika lembaga telah mendapatkan komitmen pegawainya, berarti lembaga secara otomatis akan mendapatkan pegawai yang setia serta berusaha keras untuk mencapai tujuan lembaga dan percaya pada nilai-nilai lembaga. Rao (1996) mengemukakan bahwa kekuatan organisasi adalah pada orang-orangnya. Apabila orangorang itu diperhatikan secara tepat dengan penghargaan yang tinggi, kemudian kemampuan mereka dikembangkan secara kontinyu, maka organisasi akan menjadi lebih dinamis dan berkembang.

Untuk mencapai tingkat komitmen yang diharapkan, maka Universitas Muhamadiyah Cirebon harus menjaga agar segala aktivitas yang ada di dalam lembaga berjalan dengan baik, karena komitmen pegawai terutama Dosen sebagai tenaga pendidik merupakan jantung sebuah lembaga. Jantung ini bukan hanya untuk menentukan persoalan hidup dan mati lembaga tersebut, namun juga menjadi kunci utama lembaga agar dapat berkembang secara produktif dan kreatif.

Persoalan ini harus disadari oleh Universitas Muhamadiyah Cirebon, sehingga Universitas Muhamadiyah Cirebon harus menerapkan "performance standard" bagi setiap unit kegiatan. Dengan memberlakukan sistem ini, maka lembaga dapat mengukur dan memacu upaya peningkatan kompensasi kerja, baik untuk setiap individu maupun unit kerja, dan pada akhirnya akan memperoleh suatu kepuasan kerja pegawai terutama bagi para Dosen.

Upaya mengukur dan memacu kepuasan kerja itu tentu saja tidak lepas dari sistem kompensasi, pemantauan atau monitoring dan evaluasi kerja pada setiap akhir rentang waktu yang telah ditetapkan. Misalnya pada akhir tahun, berapa besar produktivitas yang telah dilaksanakan jika dibandingkan dengan performance standard yang telah ditetapkan. Namun demikian, bukan berarti dengan pemberlakuan sistem tersebut kemudian membuat para pegawai terutama Dosen hanya berorientasi pada hasil kerja. Universitas Muhamadiyah Cirebon harus melakukan monitoring kualitas Dosen, metode pengajaran dan mengacu pada kebijakan-kebijakan yang telah ditetapkan 
oleh Pemerintah. Sehubungan dengan itu, penilaian kepuasan kerja perlu dikaitkan dengan kebijakan penggajian, kebijakan pembayaran bonus dan kualitas lingkungan kerja yang disediakan oleh lembaga tersebut.

Menyadari pentingnya sumber daya manusia, maka Antonius Purba (2005) mengemukakan bahwa sumber daya manusia yang produktif dan inovatif didapat bilamana SDM itu berada dalam kondisi yang menunjang psikologikal dan pysical yang memungkinkan manusia dapat berkonsentrasi pada profesi dan tantangan pekerjaannya masing-masing. Sehubungan dengan pertimbangan itu, maka pihak Universitas Muhamadiyah Cirebon perlu memperhatikan reward, hukuman, dan hadiah di lingkungan atau kondisi kerja pegawai terutama terhadap Dosen.

Sejalan dengan hirarki kebutuhan yang dikemukakan oleh Maslow maka kebutuhan tingkat pertama pegawai yang diharapkan dipenuhi organisasi adalah kebutuhan fisiologis. Kebutuhan fisiologis yang harus dipenuhi adalah pemberian imbalan kompensasi yang dibayarkan dari pihak lembaga kepada pegawai. Pegawai senantiasa mengharapakan penghargaan atas setiap prestasi yang telah dicapainya dan jika prestasi itu dihargai oleh pihak lembaga atau organisasi maka pegawai akan memelihara prestasi tersebut bahkan akan meningkatkannya di masa mendatang. (Hasibuan, 2017)

Walaupun harus diakui bahwa tidak selamanya imbalan atau kompensasi yang tinggi selalu memberikan kepuasan kerja dan komitmen yang tinggi. Akan tetapi kepuasan pegawai menjadi alasan untuk berprestasi tinggi, sedang atau rendah. Dengan demikian salah satu faktor yang dapat menghilangkan ketidakpuasan dan meningkatkan komitmen adalah pemberian kompensasi yang memadai, bonus dan lingkungan kerja menyenangkan.

\section{Rumusan Masalah}

Berdasarkan latar belakang dan fokus penelitian diatas, maka peneliti membuat rumusan masalah dalam penelitian ini sebagai berikut:
1. Bagaimana pengaruh kompensasi terhadap komitmen Dosen dalam mengajar pada Universitas Muhammadiyah Cirebon?

2. Bagaimana pengaruh kepuasan kerja terhadap komitmen Dosen dalam mengajar pada Universitas Muhammadiyah Cirebon?

3. Bagaimana pengaruh kompensasi dan kepuasan kerja terhadap komitmen Dosen dalam mengajar pada Universitas Muhammadiyah Cirebon?

\section{TINJAUAN PUSTAKA}

\section{Kompensasi}

Menurut Hasibuan (2017) kompensasi adalah semua pendapatan yang berbentuk uang, barang langsung atau tidak langsung yang diterima pegawai imbalan atas jasa yang diberikan kepada perusahaan.

Sedangkan menurut Luis R. Gomez Mejia, David B. Balkin, dan Robert L. Cardy (2001) menyatakan bahwa Total compensation is the package of quantitable rewards and employee receives for his or her labors. Includes three components: base compensation, pay incentives, and indirect compensation / benefits.

Jadi dapat disimpulkan secara umum bahwa kompensasi adalah bentuk penghargaan baik berupa uang maupun tidak, yang diterima oleh pegawai atas kontribusi yang telah mereka berikan kepada perusahaan dalam sistem hubungan kerja.

\section{Kepuasan Kerja}

\section{Menurut}

Robbins

(2003) mendefinisikan kepuasan kerja sebagai "The term of job satisfaction refers to an individual's general attitude toward his or her job. A person with a high level of job satisfaction holds positive attitudes about the job, whole a person who unsatisfied with his or her job holds negative attitudes about job."

Definisi lain mengenai konsep kepuasan kerja menurut Sweeny dan Mc.Farlin, (2002) adalah “...job satisfaction is a result of a psychological 
comparison process. Basically, employee asses the extent to which various aspect of their jobs measure up to what they desire. In general, the greater gap between what employees has and what they want from their jobs, the less satisfied they are. Employees tend to be most satified with their job when what they have matches what they want."

Berdasarkan tiga definisi di atas, kita dapat melihat bahwa kepuasan kerja adalah sekumpulan perasaan yang dialami karyawan terhadap pekerjaannya. Kepuasan juga berhubungan erat dengan ekspektasi karyawan tentang apa yang seharusnya mereka terima sebagai imbalan kerja. Jika apa yang diharapkan sesuai dengan apa yang diterima, maka kepuasan karyawan akan berada pada titik optimal. Sebaliknya jika apa yang diterima lebih rendah daripada yang diharapkan, maka kepuasan kerja karyawan akan rendah.

\section{Komitmen}

Menurut Zurnali (2010), komitmen merupakan perasaan yangkuat dan erat dari seseorang terhadap tujuan dan nilai suatu organisasi dalam hubungannya dengan peranmereka terhadap upaya pencapaian tujuan dan nilai-nilai tersebut.

Komitmen menurut Robbins (2003) adalah sebagai suatu keadaan dimana seorang karyawan memihak pada suatu organisasi tertentu dan tujuan-tujuannya serta berniat memerihara keanggotaan dalam organisasi tersebut. Robbins (2003) menyatakan output yang diharapkan dari studi perilaku organisasional adalah produktivitas, tingkat kemangkiran yang rendah serta kepuasan kerja.

Komitmen terhadap pekerjaan dan organisasi tempat bekerja merupakan subyek yang saat ini mendapatkan peningkatan perhatian dari peneliti perilaku organisasional. Jadi komitmen ini merupakan gambaran kesetian para anggota organisasi termasuk pimpinan organisasi terhadap organisasinya.

\section{METODOLOGI PENELITIAN}

\section{Metode Penelitian}

Metode penelitian yang dilakukan dalam penelitian ini adalah dengan metode kuantitatif untuk mengolah data-data yang diperoleh dari lokasi penelitian, merupakan data yang berbentuk angka atau data kuantitatif yang diangkat. Pendekatan kuantitatif yaitu pencarian data atau informasi dari realitas permasalahan yang ada dengan mengacu pada pembuktian konsep atau teori yang digunakan (Sugiyono, 2011).

\section{Populasi dan Sampel}

Sudjana (2002) memberikan pengertian bahwa Populasi adalah totalitas semua nilai yang mungkin baik hasil menghitung ataupun pengukuran, kuantitatif maupun kualitatif daripada karakteristik tertentu mengenai sekumpulan objek yang lengkap dan jelas yang ingin dipelajari sifat-sifatnya.

Populasi dalam penelitian ini adalah Dosen Tetap dan Dosen Luar Biasa yang mengajar di Universitas Muhamadiyah Cirebon. Jumlah Dosen Tetap sebanyak 128 orang dan jumlah Dosen Luar Biasa sebanyak 129 orang, sehingga total Dosen yang mengajar di Universitas Muhammadiyah Cirebon sebanyak 257 orang.

Untuk menentukan besarnya ukuran sampel mengacu kepada teori yang dikemukakan oleh Suharsimi Arikunto (2002) yang menyatakan bahwa apabila subyek kurang dari 100, maka lebih baik diambil seluruhnya, tetapi apabila jumlah subyek lebih dari 100 dapat diambil antara 10-15\% atau 20-25\% atau lebih. Berdasarkan pendapat tersebut, sampel yang diambil dalam penelitian ini adalah 20 $\%$ x 257 Dosen UMC, sehingga sampel yang akan digunakan sebanyak 51 Dosen secara proporsional berdasarkan 5 Fakultas.

\section{Teknik dan Prosedur Pengumpulan Data}

Teknik pengumpulan data pada penelitian ini menggunakan berbagai 
macam teknik, sumber dan cara. Adapun teknik yang digunakan yaitu menyebarkan kuesioner. Instrumen pengumpulan data peneliti menggunakan alat bantu yang terdiri dari pedoman data kepegawaian umc dan pedoman penyusunan kuesioner.

\section{HASIL PENELITIAN DAN PEMBAHASAN}

\section{a. Uji Validitas}

Uji validitas dilakukan untuk menguji kesahihan pertanyaan yang dijadikan kuisioner. Analisis validitas dilakukan dengan menggunakan korelasi product moment dengan menggunakan IBM SPSS. Hasil pengujian validitas kompensasi, kepuasan kerja dan komitmen dosen dapat dilihat pada :

Tabel 3.1. Tabel Pengujian Validitas

\begin{tabular}{|c|c|c|c|c|}
\hline Variabel & Pernyataan & r hitung & $r$ tabel & $\begin{array}{c}\text { Keterang } \\
\text { an }\end{array}$ \\
\hline \multirow[t]{5}{*}{ Kompensasi } & $\begin{array}{l}\text { Sistem } \\
\text { kompensasi } \\
\text { dan } \\
\text { penghargaan }\end{array}$ & 0,891 & 0,279 & Valid \\
\hline & $\begin{array}{l}\text { Sistem royalti } \\
\text { hak cipta }\end{array}$ & 0,870 & 0,279 & Valid \\
\hline & $\begin{array}{l}\text { Kenyaman } \\
\text { lingkungan } \\
\text { kerja }\end{array}$ & 0,896 & 0,279 & Valid \\
\hline & Loyalitas dosen & 0,860 & 0,279 & Valid \\
\hline & $\begin{array}{l}\text { Kelengkapan } \\
\text { Fasilitas } \\
\text { mengajar }\end{array}$ & 0,801 & 0,279 & Valid \\
\hline \multirow[t]{5}{*}{$\begin{array}{l}\text { Kepuasan } \\
\text { Kerja }\end{array}$} & $\begin{array}{l}\text { Metode } \\
\text { pengajaran } \\
\text { mandiri }\end{array}$ & 0,908 & 0,279 & Valid \\
\hline & $\begin{array}{l}\text { Kepuasan } \\
\text { terhadap gaji }\end{array}$ & 0,894 & 0,279 & Valid \\
\hline & $\begin{array}{l}\text { Kenyamanan } \\
\text { mengajar }\end{array}$ & 0,865 & 0,279 & Valid \\
\hline & Sistem Karir & 0,902 & 0,279 & Valid \\
\hline & $\begin{array}{l}\text { Kerjasama } \\
\text { sesama dosen }\end{array}$ & 0,888 & 0,279 & Valid \\
\hline \multirow{5}{*}{$\begin{array}{l}\text { Komitmen } \\
\text { Dosen }\end{array}$} & Kendali mutu & 0,775 & 0,279 & Valid \\
\hline & $\begin{array}{l}\text { Penelitian } \\
\text { dosen }\end{array}$ & 0,688 & 0,279 & Valid \\
\hline & Loyalitas dosen & 0,833 & 0,279 & Valid \\
\hline & $\begin{array}{l}\text { Dampak } \\
\text { kompensasi }\end{array}$ & 0,759 & 0,279 & Valid \\
\hline & $\begin{array}{l}\text { Model } \\
\text { kepemimpinan }\end{array}$ & 0,804 & 0,279 & Valid \\
\hline
\end{tabular}

Sumber dari data primer diolah 2016

Berdasarkan tabel 3.1 Dapat diketahui hasil perhitungan validitas diperoleh $r_{\text {hitung }}$ pada setiap pertanyaan pada variabel kompensasi, kepuasan kerja dan komitmen dosen adalah lebih besar dibandingkan $r_{\text {tabel }}$ (Tabel $r$ Product-Moment) yaitu sebesar 0,279 , sehingga dapat dikatakan bahwa pernyataan pada variabel penelitian adalah valid sehingga dapat dijadikan instrument penelitian.

\section{b. Uji Reliabilitas}

Uji reliabilitas dilakukan dengan rumus alpha cronbach dengan menggunakan IBM SPSS. Hasil perhitungan dengan menggunakan IBM SPSS Cronbach alpha pada kompensasi, kepuasan kerja dan komitmen dosen, sebagai berikut.

Tabel 3.2. Pengujian Reliabilitas

\begin{tabular}{lccc}
\hline Variabel & $\begin{array}{c}\text { Cronbach } \\
\text { Alpha }\end{array}$ & Keterangan teria \\
\hline Kompensasi & 0,819 & Relialibel & angat Tinggi \\
$\begin{array}{l}\text { Kepuasan } \\
\text { Kerja }\end{array}$ & 0,824 & Relialibel & angat Tinggi \\
$\begin{array}{l}\text { Komitmen } \\
\text { Dosen }\end{array}$ & 0,799 & Relialibel & Tinggi \\
\hline
\end{tabular}

Sumber dari data primer diolah 2016

Berdasarkan tabel 3.2 diperoleh nilai Cronbach alpha kompensasi, kepuasan kerja dan komitmen dosen > 0,600, maka semua variabel dinyatakan relialibel dengan kriteria tinggi.

\section{c. Uji Asumsi Klasik}

\section{Uji Normalitas}

Uji normalitas dilakukan dengan tujuan untuk menguji apakah dalam sebuah model regresi, variabel dependen atau keduanya mempunyai distribusi normal ataukah tidak. Model regresi yang baik yaitu distribusi data normal atau mendekati normal.

Uji ini dapat dilakukan menggunakan uji Kolmogorov-Smirnov dengan kriteria sebagai berikut :

Hipotesis Statistik

- Ho : Data berdistribusi normal

- Ha : Data tidak berdistribusi normal Kriteria pengambilan pengujian dengan melihat angka probabilitas, dengan ketentuan sebagai berikut :

- Probabilitas > 0,05 maka Ho diterima

- Probabilitas <0,05 maka Ho ditolak 
Tabel 3.3. Uji Normalitas

One-Sample Kolmogorov-Smirnov Test

\begin{tabular}{|ll|r|}
\hline & & \multicolumn{1}{|c|}{$\begin{array}{c}\text { Standardized } \\
\text { Residual }\end{array}$} \\
\hline $\mathrm{N}$ & & 51 \\
Normal Parameters & Mean &, 0000000 \\
\multirow{3}{*}{ Most Extreme Differences } & Std. Deviation &, 97979590 \\
\cline { 2 - 3 } & Absolute &, 090 \\
\cline { 2 - 3 } & Positive &, 090 \\
& Negative &,- 063 \\
\cline { 3 - 3 } & &, 090 \\
Test Statistic &, $200^{\text {c,d }}$ \\
\hline
\end{tabular}

a. Test distribution is Normal

b. Calculated from data.

c. Lilliefors Significance Correction.

$\mathrm{d}$. This is a lower bound of the true significance.

Berdasarkan tabel dapat dilihat nilai signifikan pada Unstandardized Residual sebesar 0,200. Karena nilai signifikan semuanya berada di atas 0,05 berarti Ho diterima yang artinya data penelitian berdistribusi normal.

Berikut ini adalah gambar dari hasil pengujian normalitas data yang ditunjukan dalam gambar sebagai berikut :

Gambar 3.1. Gambar Model

Regresi

Scatterplot

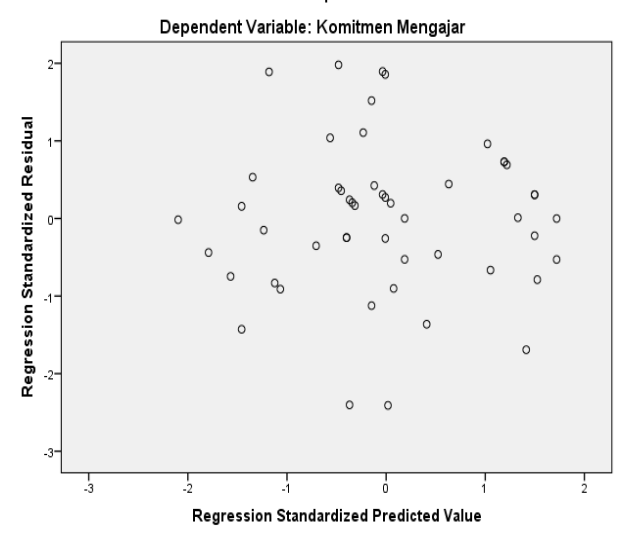

Berdasarkan gambar dapat terlihat titik-titik menyebar di sekitar garis diagonal, serta penyebarannya mengikuti garis diagonal, sehingga regresi ini dapat dikatakan mendekati normal. Maka model regresi diagonal layak dipakai.

\section{Uji Multikolonieritas}

Uji Multikolonieritas dilakukan untuk mengetahui apakah model regresi ditemukan adanya korelasi antar variabel bebas. Bila terjadi korelasi, maka terdapat masalah multikolonieritas yang harus diatasi.

Jika nilai variance inflation factor (VIF) $>10$ dan nilai tolerance $<0,1$ maka terdapat multikolonieritas, sedangkan jika nilai VIF $<10$ dan nilai tolerance $>0,1$ maka tidak terjadi multikolonieritas.

Tabel 3.4. Uji Multikolonieritas Coefficients $^{\mathbf{a}}$

\begin{tabular}{|c|c|c|c|c|c|c|c|}
\hline \multirow[b]{2}{*}{ Model } & \multicolumn{2}{|c|}{$\begin{array}{c}\text { Unstandardized } \\
\text { Coefficients }\end{array}$} & \multirow{2}{*}{$\begin{array}{c}\text { Standardi } \\
\text { zed } \\
\text { Coefficie } \\
\text { nts }\end{array}$} & \multirow[b]{2}{*}{$\mathrm{t}$} & \multirow[b]{2}{*}{$\begin{array}{l}\mathrm{Si} \\
\mathrm{g} .\end{array}$} & \multicolumn{2}{|c|}{$\begin{array}{l}\text { Collinearity } \\
\text { Statistics }\end{array}$} \\
\hline & B & $\begin{array}{l}\text { Std. } \\
\text { Error }\end{array}$ & & & & Tolerance & VIF \\
\hline $\begin{array}{l}1 \text { (Constant } \\
\quad)\end{array}$ & 3,981 & 1,621 & & $\begin{array}{r}2,45 \\
6\end{array}$ & $\begin{array}{r}, 0 \\
18\end{array}$ & & \\
\hline $\begin{array}{l}\text { Kompens } \\
\text { asi }\end{array}$ &, 510 & , 102 &, 540 & $\begin{array}{r}4,98 \\
2\end{array}$ & $\begin{array}{l}, 0 \\
00\end{array}$ &, 595 & 1,681 \\
\hline $\begin{array}{l}\text { Kepuasan } \\
\text { Kerja }\end{array}$ & ,291 & ,088 & ,358 & $\begin{array}{r}3,30 \\
1\end{array}$ & $\begin{array}{r}, 0 \\
02\end{array}$ & ,595 & $1, \overline{0} 1$ \\
\hline
\end{tabular}

a. Dependent Variable: Komitmen Mengajar

Berdasarkan tabel dapat dilihat bahwa nilai VIF untuk variabel kompensasi dan kepuasan kerja memiliki nilai 1,681 dimana nilai tersebut $<10$, dan nilai tolerance yaitu 0,595 dimana $0,595>0,1$. Dengan demikian dapat disimpulkan bahwa model regresi tersebut tidak terdapat multikolonieritas, artinya tidak adanya variabel bebas yang saling berkolerasi.

\section{Uji Heteroskedastisitas}

Uji Heteroskedastisitas dilakukan untuk mengetahui apakah dalam sebuah model regresi terjadi ketidaksamaan varians dari residual suatu pengamatan ke pengamatan lain. Jika variance dari nilai residual dari satu pengamatan ke pengamatan yang lain tetap, maka disebut dengan Homoskedastisitas. Dan jika varians berbeda dari satu pengamatan ke pengamatan yang lainnya, maka disebut Heteroskedastisitas. Model regresi yang baik adalah yang 
Hemoskedastisitas atau tidak terjadi Heteroskedastisitas.

Adapun hasil pengujian heteroskedastisitas terhadap variabel kompensasi $\left(\mathrm{X}_{1}\right)$, kepuasan kerja $\left(\mathrm{X}_{2}\right)$ dan komitmen mengajar (Y) dengan menggunakan program SPSS, yaitu sebagai berikut :

Tabel 3.5. Uji Heteroskedastisitas

Coefficients $^{\mathbf{a}}$

\begin{tabular}{|c|c|c|c|c|c|c|c|}
\hline \multirow[b]{2}{*}{ Model } & \multicolumn{2}{|c|}{$\begin{array}{l}\text { Unstandardize } \\
\text { d Coefficients }\end{array}$} & \multirow{2}{*}{$\begin{array}{c}\text { Standardized } \\
\text { Coefficients } \\
\text { Beta }\end{array}$} & \multirow[b]{2}{*}{$\mathrm{t}$} & \multirow[b]{2}{*}{ Sig. } & \multicolumn{2}{|c|}{$\begin{array}{l}\text { Collinearity } \\
\text { Statistics }\end{array}$} \\
\hline & B & $\begin{array}{l}\text { Std. } \\
\text { Error }\end{array}$ & & & & $\begin{array}{c}\text { Tolera } \\
\text { nce }\end{array}$ & VIF \\
\hline 1 (Constant) & 1,882 & 1,057 & & 1,780 &, 081 & & \\
\hline Kompensasi &,- 011 & ,067 &,- 031 &,- 164 & ,870 & ,595 & 1,681 \\
\hline $\begin{array}{l}\text { Kepuasan } \\
\text { Kerja }\end{array}$ &,- 015 & 057, &,- 048 &,- 256 & ,799 & ,595 & 1,681 \\
\hline
\end{tabular}

a. Dependent Variable: ABRES

Apabila nilai signifikansi (Sig.) > 0,05 maka tidak terjadi gejala Heteroskedastisitas. Dari output di atas, maka tampak bahwa ketiga variabel tidak ada gejala heteroskedastisitas karena Sig. $>0,05$.

\section{d. Pengujian Hipotesa}

Pengujian hipotesis dilakukan dengan level of significance $95 \%$ atau $\alpha=0,05$. Hipotesis diterima jika nilai signifikansi lebih kecil dari 0,05.

Tabel Nilai 3.6. Unstandardized Coefficients (B) dan level of significance

\begin{tabular}{clcccc}
\hline \multicolumn{7}{c}{ Variabel } & B & Sig & Kesimpulan \\
\hline 1 & $\begin{array}{l}\text { Kompensasi } \rightarrow \\
\text { Dosen Komitmen }\end{array}$ & 0,725 & 0,000 & Signifikan \\
2 & $\begin{array}{l}\text { Kepuasan Kerja } \\
\text { Komitmen Dosen } \\
3\end{array}$ & $\begin{array}{l}\text { Kompensasi dan Kepuasan } \\
\text { Kerja Komitmen Dosen }\end{array}$ & 0,570 & 0,000 & Signifikan \\
\hline
\end{tabular}

\section{Uji t dan Uji F}

Terdapat tiga kesimpulan yang dapat diambil dari perhitungan uji $\mathrm{t}$ dan uji $\mathrm{F}$, yaitu sebagai berikut :

1. Terdapat pengaruh yang signifikan dan positif antara Kompensasi terhadap Komitmen Dosen. Keberartian pengaruh Kompensasi terhadap Komitmen Dosen dapat dilihat dari hasil uji t yaitu thitung sebesar 8,377 > 1,677 maka Ho ditolak, Ha diterima, sedangkan indek determinasi yang disesuaikan sebesar $58,9 \%$ sisanya $41,1 \%$ dipengaruhi oleh faktor lain yang tidak diteliti.

2. Terdapat pengaruh yang signifikan dan positif antara Kepuasan Kerja terhadap Komitmen Dosen. Keberartian hubungan Kepuasan Kerja terhadap Komitmen Dosen dibuktikan dengan uji t yaitu yang dihitung sebesar sebesar 6,884 > 1,677 maka Ho ditolak, Ha diterima, sedangkan indek determinasi yang disesuaikan sebesar 49,2\% sisanya $51,8 \%$ dipengaruhi oleh faktor lain yang tidak diteliti.

Terdapat pengaruh yang signifikan dan positif secara bersama-sama antara Kompensasi dan Kepuasan Kerja terhadap Komitmen Dosen, hal ini dapat dibuktikan dengan uji $\mathrm{F}$ yaitu nilai $\mathrm{F}$ hitung sebesar 47,624>3,18 dan nilai indeks determinasi yang disesuaikan $66,5 \%$ sisanya $33,5 \%$ dipengaruhi oleh faktor lain yang tidak diteliti.

\section{A. Kesimpulan}

\section{KESIMPULAN}

1. Kompensasi berpengaruh secara signifikan dan positif terhadap komitmen Dosen dalam mengajar di Universitas Muhammadiyah Cirebon. Hal ini dibuktikan dengan level signifikansi 0,05 didapatkan B sebesar 0,725 dan sig sebesar 0,000. Dengan sig $0,000<0,05$, maka Kompensasi berhubungan signifikan dan positif terhadap Komitmen Dosen dapat diterima. Sehingga semakin tinggi nilai kompensasi yang diberikan oleh UMC akan meningkatkan komitmen dosen dalam mengajar di Universitas Muhammadiyah Cirebon.

2. Kepuasan kerja berpengaruh secara signifikan dan positif terhadap komitmen Dosen dalam mengajar di Universitas Muhammadiyah Cirebon. Hal ini dibuktikan dengan level signifikansi 0,05 didapatkan B sebesar 0,570 dan sig sebesar 0,000. Dengan sig 0,000<0,05, maka Kepuasan Kerja berhubungan signifikan dan positif terhadap Komitmen Dosen dapat 
diterima. Sehingga semakin tinggi kepuasan kerja yang dicapai oleh dosen akan meningkatkan komitmen dosen dalam mengajar di Universitas Muhammadiyah Cirebon.

3. Kompensasi dan kepuasaan kerja secara simultan berpengaruh secara signifikan dan positif terhadap komitmen Dosen dalam mengajar di Universitas Muhammadiyah Cirebon. Hal ini dibuktikan dengan level signifikansi 0,05 didapatkan B sebesar 0,390 dan sig sebesar 0,000. Dengan sig $0,000<0,05$, maka Kompensasi dan Kepuasan Kerja berhubungan signifikan dan positif terhadap Komitmen Dosen dapat diterima. Sehingga semakin tinggi kompensasi dan kepuasan kerja yang dicapai oleh dosen akan meningkatkan komitmen dosen dalam mengajar di Universitas Muhammadiyah Cirebon.

\section{B. Saran}

1. Berdasarkan penelitian yang telah dilakukan bahwa ada hubungan yang signifikan dan positif antara pemberian kompensasi terhadap peningkatan komitmen Dosen dalam mengajar, maka penulis menyarankan kepada Universitas Muhammadiyah Cirebon untuk meningkatkan nilai kompensasi yang tinggi kepada Dosen, sehingga dengan pemenuhan kebutuhan hidup Dosen yang layak akan meningkatkan komitmen Dosen dalam mengajar. Dengan demikian pemikiran dosen tidak akan bercabang untuk memenuhi kebutuhan hidup dan hanya berkonsentrasi dalam pengembangan ilmu pengetahuan dan teknologi.

2. Berdasarkan penelitian yang telah dilakukan bahwa ada hubungan yang signifikan dan positif antara kepuasan kerja yang diperoleh Dosen terhadap peningkatan komitmen Dosen dalam mengajar, maka penulis menyarankan kepada Universitas Muhammadiyah Cirebon untuk meningkatkan kepuasan kerja Dosen dengan melengkapi sarana dan prasarana dalam mengajar, sehingga dengan pemenuhan fasilitas yang lengkap akan meningkatkan komitmen Dosen dalam mengajar.

3. Setelah dilakukan penelitian ini, maka Universitas Muhammadiyah Cirebon sebaiknya melakukan peningkatan nilai kompensasi yang diberikan serta peningkatan kepuasan kerja Dosen secara bersama-sama untuk meningkatkan komitmen Dosen dalam mengajar. Hal ini bertujuan agar Universitas Muhammadiyah Cirebon mampu mencetak Sarjana-Sarjana yang berkualitas dan dapat diserap oleh dunia industri dan usaha.

\section{DAFTAR PUSTAKA}

Aldag, J. Ramon, Loren W. Kuzuhara, (2002). Organizational Behaviour and Management: An Integrated Skill Approach. South Western.

Arikunto, S. (2010). Metodologi Penelitian Suatu Pendekatan Proposal. Jakarta : PT. Rineka Cipta.

Davis K. \& Newstrom W.J. (2006). Perilaku Dalam Organisasi. Edisi ketujuh. Jakarta: Erlangga.

De Cenzo, A, David, Stephen P. Robbins. (2009). $6^{\text {th }}$ Edition. Human Resource Management. John Wiley \& Sons Inc.

Dessler, Garry. (2007). Manajemen Sumber Daya Manusia. Edisi Bahasa Indonesia. Jakarta: Prehallindo.

George, J.M., G.R. Jones (2002). $3^{\text {rd }}$ edition. Organizational Behaviour. New Jersey: Prentice-Hall International Inc.

Gibson James L., Ivancevich John, M. Donnely James H.Jr (2000). $10^{\text {th }}$ Edition. Organization. McGraw Hill.

Gomez - meija, R. Luis, David B. Balkin, Robert L. Cardy. (2001). $3^{\text {rd }}$ Edition. Human Resource Management. 
Prentice-Hall.

Handoko, T.H. (2006). Manajemen

Personalia dan Sumber Daya

Manusia. Yogyakarta : BPFE.

Hasibuan, Malayu, S.P. (2017). Manajenmen Sumber Daya

Manusia. Jakarta: Bumi Aksara.

Hasibuan, (2010). Pengukuran kompensasi. Jakarta Bulan sabit.

Hodge., G.J. \& Anthony, W.P. (1991). Organization Theory: A Strategic Approach $4^{\text {th }}$ Edition. Allyn and Bacon Inc.

Wardani. (2009). Riset Sumber Daya Manusia. Jakarta : PT. Gramedia Pustaka Utama.

Jones, R. Garreth, George M. Jennifer. (2003). $3^{\text {rd }}$ Edition. Contemporary Management. McGraw-Hill.

John, Pierce L, Donald G. Gardner \& Randall B. Dunham (2002). Management Organizational Behaviour. USA. South Werstern: Thomson Learning.

Kanter, R.M. (1968). Commitment And Social Organization: A Study at Commitment Mechanism in Utopianj Communities. American Sociological Review.

Luthans, F. (2005). 10 $0^{\text {th }}$ Edition. Organizational Behavior. New York: McGraw Hill Co, Inc.

Martoyo, S. (2000). Manajemen Sumber Daya Manusia. Yogyakarta: BPFE.

Mathis, Robert L \& Jackson John H. (2000). Human Resources Management. $9^{\text {th }}$ Edition. South Western College Publishing.

Mowday, R.T., Porter, L.W., and Steers, R.M. (1982). Employee Organization
Linkage The Psychology of Commitment, Absenteeism, and Turnover. New York: Academic Press.

Newstrom, W. John Keith Davis (2002). $11^{\text {th }} \quad$ Edition. Organizational Behavior: Human Behavior at Work. McGraw Hill.

Purba, Antonius. (2005). Sistem Penggajian Imbal Jasa. Jakarta : PT. Grasindo

Rahmat, Jalaluddin. (2005). Metode Penelitian Komunikasi. Bandung: PT. Remaja Rosdakarya.

Rao, T.V. (1996). Penilaian Prestasi Kerja. Edisi Bahasa Indonesia. Jakarta: Pustaka Binaman Pressindo.

Robbins, Stephen. P. (2006). Perilaku Organisasi. Edisi Bahasa Indonesia. Jakarta: PT. Indeks.

Robbins, Stephen P. (2003) Terj. Sokadijo. Organizational Behavior. $10^{\text {th }}$ Edition. Prentice-Hall, Inc.

Saifuddin, Azwar. (2007). Reliabilitas dan Validitas. Edisi ke-3. yogyakarta: Pustaka Pelajar.

Simamora, H. (2007). Manajemen Sumber Daya Manusia. Edisi Kedua. Yogyakarta: STIE YKPN.

Sudjana. (2002). Metode Statistika. Edisi keenam. Bandung : Tarsito.

Sugiyono. (2011). Statistik Untuk Penelitian. Bandung: Penerbit CV. Alfabeta.

Zurnali, Cut. 2010. Learning Organization, Competency, Organizational Commitment, And Customer Orientation : Knowledge Worker Kerangka Riset Manajemen SumberDaya Manusia Masa Depan. Bandung : Unpad Press. 
